\title{
ANTERIOR CEREBRAL ARTERY: AN ANATOMICAL STUDY
}

\section{Dhanalakshmi V ${ }^{1}$, Suresh Kumar T *2, Arun Kumar K ${ }^{3}$, Sathish Kumar $\mathrm{S}^{4}$.}

${ }^{1}$ Associate Professor, Department of Anatomy, Govt. Thoothukudi Medical College, Thoothukudi, Tamilnadu, India.

${ }^{* 2}$ Associate Professor, Department of Anatomy, Govt. Vellore Medical College, Vellore, Tamilnadu, India.

${ }^{3}$ Associate Professor, Department of Anatomy, Dhanalakshmi Srinivasa Medical College, Perambalur, Tamilnadu, India.

${ }^{4}$ Associate Professor, Department of Anatomy, Govt. Dharmapuri Medical College, Dharmapuri, Tamilnadu, India.

\section{ABSTRACT}

Introduction: Anterior cerebral artery (ACA), the smaller terminal branch of the internal carotid artery is significant clinically due to its wide variety of complexity and technical difficulty in surgical procedures.

Methods and materials: This study was done in 50 embalmed adult brain hemispheres at Institute of Anatomy, Madras Medical College, Tamilnadu. The study of the anterior cerebral artery was undertaken to observe the mode of origin, its course and branches.

Results: Anterior cerebral artery originated from the internal carotid artery in $100 \%$ of specimens. ACA passed above optic nerve in 32 specimens (64\%), above optic chiasma in 16 specimens (32\%) and above optic tract in 2 specimens (4\%). The average length of A1 segment of right ACA and left ACA were $14.3 \mathrm{~mm}$ and $13.7 \mathrm{~mm}$ respectively. The difference in diameter of $1 \mathrm{~mm}$ or more on both sides was observed in $8 \%$. Left A1 segment was duplicated in 1 specimen (2\%). Median artery of corpus callosum and Azygous anterior cerebral artery were found in one specimen each. Fenestration of A2 segment was observed in one specimen (4\%). Heubner's artery arose from A2 segment in $32(64 \%)$ specimens, from A1 segment in $6(12 \%)$ specimens and from the level of ACoA in 12 (24\%) specimens. The orbitofrontal artery originated on an average distance of $5.73 \mathrm{~mm}$ on right side and average of $4.82 \mathrm{~mm}$ on left side. Frontopolar artery(FPA) originated at a distance of about $20.2 \mathrm{~mm}$ on right side and $17.6 \mathrm{~mm}$ on left side. Callosomarginal artery and pericallosal artery were found in all the specimens. In one specimen the right FPA originated from callosomarginal artery.

Conclusion: Rapidly advancing fields of vascular neurosurgery and interventional neuroradiology techniques require a thorough understanding of the anatomy. This detailed study done under various parameters would benefit the radiologists and neurosurgeons.

KEY WORDS: Anterior cerebral artery, Aneurysm, Frontopolar artery, Heubner's artery, Orbitofrontal artery.

Address for Correspondence: Dr. Suresh Kumar. T, Associate Professor, Department of Anatomy, Govt. Vellore Medical College, Vellore, Tamilnadu, India. Mobile: 9443746455

E-Mail: rajupr8@yahoo.co.in

Access this Article online

Quick Response code

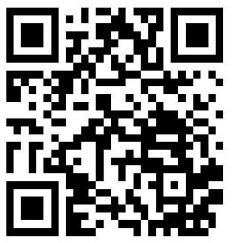

DOI: $10.16965 /$ ijar.2019.149

Journal Information

International Journal of Anatomy and Research

$$
\text { ICV for } 2016 \text { ISSN (E) 2321-4287 | ISSN (P) 2321-8967 }
$$

90.30 https://www.ijmhr.org/ijar.htm DOI-Prefix: https://dx.doi.org/10.16965/ijar

\section{(cc) $\mathrm{E}+\mathrm{Mr}-\mathrm{Bg}$}

\section{Article Information}

Received: 18 Feb 2019

Peer Review: 19 Feb 2019

Revised: None
Accepted: 07 Apr 2019

Published (O): 05 May 2019

Published (P): 05 May 2019

\section{INTRODUCTION}

Fantasy of human Anatomy is its variations.
Although many of the variations cause no disturbance in the functions of the body, they may 
be of great importance to the surgeons. Interesting variations and anomalies in the origin and course of arteries have long received the attention of anatomists, radiologists and surgeons. Anterior cerebral artery (ACA) is the smaller of the two terminal branches of the internal carotid artery. It starts at the medial end of the stem of the lateral cerebral fissure and passes anteromedially above the optic nerve to the great longitudinal fissure where it connects with its fellow by a short transverse anterior communicating artery.

The surgical nomenclature divides the vessel into three parts:

A1 - from the termination of internal carotid artery to the junction with the anterior communicating artery

A2 - from the junction with anterior communicating artery to the origin of the callosomarginal artery

A3 - distal to the origin of the callosomarginal artery (CMA). This segment is also known as the pericallosal artery

Anterior cerebral arteries give cortical and central branches. The major cortical branches are orbitofrontal artery(OFA), frontopolar artery(FPA), callosomarginal artery(CMA) and pericallosal artery(PCA). The major central branch is recurrent artery of Heubner (RAH).

The cortical branches supply the areas of the motor and somatosensory cortices which represents the lower limb. The central branches arise from its proximal portion and enter the anterior perforated substance and lamina terminalis collectively. The central branches supply the rostrum of corpus callosum, septum pellucidum, anterior part of putamen, head of caudate nucleus and the adjacent parts of internal capsule. The medial striate artery supplies the anterior part of head of caudate nucleus and adjacent regions of the putamen and internal capsule [1].

The total incidence of A1 -ACoA - distal ACA aneurysm was $34.6 \%$ [2]. Distal anterior cerebral artery (DACA) aneurysms represent about $6 \%$ of all intracranial aneurysms [3]. The aneurysm has an unusually wide variety of complexity and technical difficulty that depends on variation in parent artery anatomy, aneurysm projection and clinical presentation.

\section{MATERIALS AND METHODS}

The anatomical study of anterior cerebral artery was done at Institute of Anatomy, Madras Medical College, Chennai, Tamilnadu from 50 adult brain hemispheres obtained from twenty five adult embalmed human cadavers.

The study of the anterior cerebral artery was undertaken to study the mode of origin, its course and branches. The course of ACA was traced and its relation with optic nerve, optic chiasma and optic tract was observed. The number of A1 segment and its length were noted. The diameter of $A 1$ segment was measured with digital Vernier caliper after injecting latex into internal carotid artery.

The Recurrent Artery of Heubner(RAH) was identified and its level of origin was noted. The distal ACA was observed for the presence of variations. The origin of orbitofrontal artery, frontopolar artery and callosomarginal artery was observed and its distance of origin from ACoA junction was measured. The presence of pericallosal artery was also observed in all hemispheres.

Fig. 1: Duplicated A1 segment of left anterior cerebral artery.

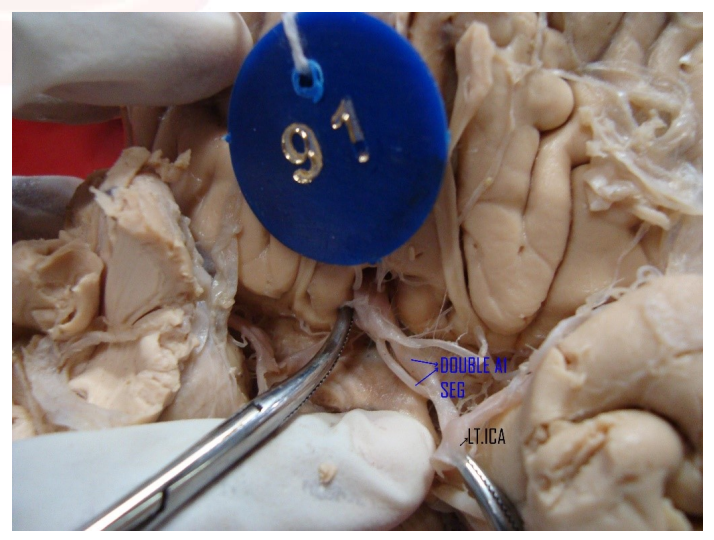

Fig. 2: MACC continuing as pericallosal artery(PCaA).

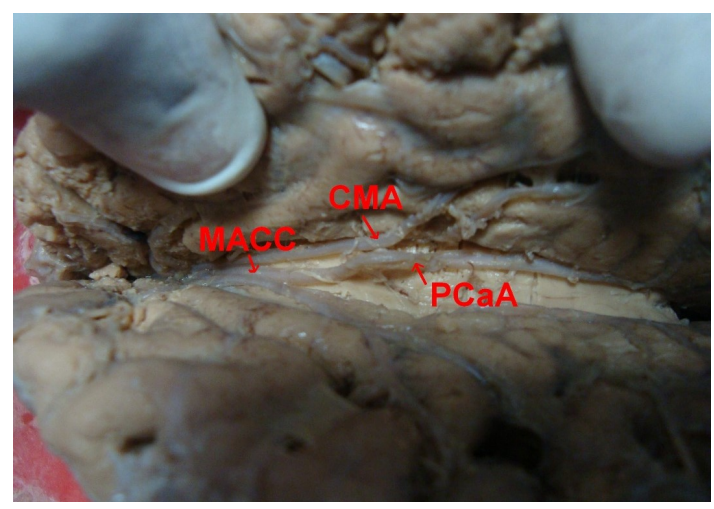


Fig. 3: Azygous ACA.

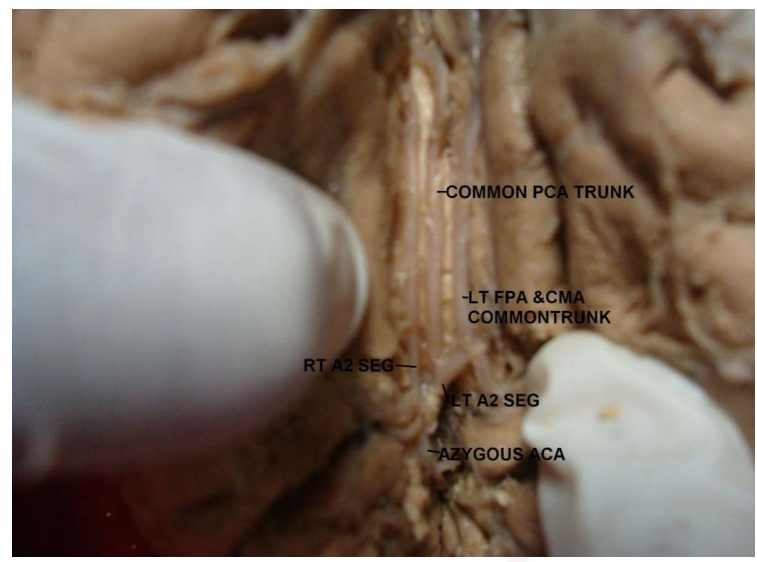

Fig. 4: Fenestrated A2 segment.

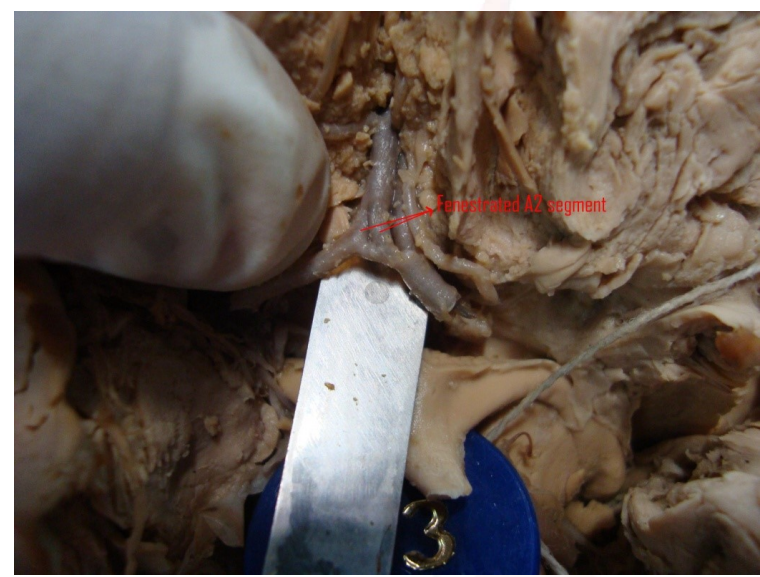

\section{RESULTS}

Anterior cerebral artery originated from the internal carotid artery in all the 50 hemispheres(100\%). ACA passed above optic nerve in 32 specimens (64\%), above optic chiasma in 16 specimens (32\%) and above optic tract in 2 specimens (4\%).

The length of $A 1$ segment of right ACA ranged from $11 \mathrm{~mm}-18 \mathrm{~mm}$ with an average of 14.3 $\mathrm{mm}$. On the left side, the length of $A 1$ segment ranged from $9 \mathrm{~mm}-18 \mathrm{~mm}$ with an average of $13.7 \mathrm{~mm}$. The diameter of right $\mathrm{A} 1$ segment ranged $0.68 \mathrm{~mm}$ to $2.23 \mathrm{~mm}$ with an average of $1.76 \mathrm{~mm}$ and the left $A 1$ segment was found to be $1.8 \mathrm{~mm}$ on average with range $0.53 \mathrm{~mm}$ to $2.57 \mathrm{~mm}$. The diameter of A1 segment with < $1.5 \mathrm{~mm}$ was found in $10 \%$ and $<1 \mathrm{~mm}$ was found in $4 \%$. The difference in diameter of $1 \mathrm{~mm}$ or more in both sides was observed in $8 \%$. Left $A 1$ segment was duplicated in 1 specimen (2\%) [ Fig:1] and its length was found to be $11 \mathrm{~mm}$ which extended from near middle of $A 1$ segment and ended in ACOA.

Median artery of corpus callosum was found in one specimen where the A1 segments were normal. The right $A 2$ segment ended with callosomarginal artery and the frontopolar artery arose from the callosomarginal artery. The median artery of corpus callosum arose from ACoA and continued as right pericallosal artery [Fig:2]. In the left side, the ACA was found normal.

Azygous anterior cerebral artery was found in one specimen [Fig:3]. A1 segments were normal on both sides. Both $A 1$ segments united to form azygous ACA with the diameter of $3.6 \mathrm{~mm}$. After $3.6 \mathrm{~cm}$ it bifurcated into right \& left branches. Right branch continued as callosomarginal artery and left branch after a distance $0.5 \mathrm{~cm}$ divided into two branches. One branch continued as callosomarginal artery and the other continued as a common trunk of pericallosal artery which after a distance of about $4.73 \mathrm{~cm}$ divided again into 2 pericallosal arteries to supply both sides.

Fenestration of A2 segment was observed in one specimen (4\%) [Fig:4].

Heubner's artery was present in all 50 specimens $(100 \%)$ and it arose from A2 segment in 32 (64\%) specimens, from A1 segment in 6 (12\%) specimens and from the level of ACoA in 12 (24\%) specimens.

In 49 specimens, the orbitofrontal artery originated from $A 2$ segment and in 1 specimen it arose from ACA at the level of ACOA along with Heubner's artery The orbitofrontal artery originated on an average distance of $5.73 \mathrm{~mm}$ on right side and $4.82 \mathrm{~mm}$ on left side from $A C O A$ with a range of 0 to $12 \mathrm{~mm}$ on right side and $0.9 \mathrm{~mm}$ to $11 \mathrm{~mm}$ on left side.

Frontopolar artery originated at a distance of about $20.2 \mathrm{~mm}$ on right side and $17.6 \mathrm{~mm}$ on left side with a range of $8 \mathrm{~mm}$ to $42 \mathrm{~mm}$ on right side and $11 \mathrm{~mm}$ to $28 \mathrm{~mm}$ on left side. In one specimen the right FPA originated from callosomarginal artery.

Callosomarginal artery originated at a distance of about $37.08 \mathrm{~mm}$ with a range of $16 \mathrm{~mm}$ to 75 $\mathrm{mm}$ on right side and an average of $36.76 \mathrm{~mm}$ with range of $20 \mathrm{~mm}$ to $60 \mathrm{~mm}$ on left side.

Pericallosal artery was found in all the specimens. In one specimen, there was a common pericallosal artery which arose from left branch 
of azygous ACA which bifurcated into right and left pericallosal artery to supply corresponding sides.

No anomalous vessel was found originating from anterior cerebral artery.

\section{DISCUSSION}

Anomalous origin of ACA was reported by various authors. Chummy S. Sinnatamby stated that occasionally both anterior cerebrals may arise from one carotid by a common stem [4]. G.J. Romanes stated that the ACA may arise from its fellow by enlargement of the ACoA[5].

The relationship of ACA with respect to optic nerve, optic chiasma and optic tract is clinically significant as pressure from any one of these arteries may therefore produce various defects in visual fields [6]. J. Peltier et al observed that, the pre-communicating parts of both anterior cerebral arteries coursed inferior to the ipsilateral optic nerves [7].

A1 segment of ACA can be duplicated, hypoplastic or absent. Incidence of duplication was 7.5\% [8]. Incidence of hypoplastic or absent A1 segment was $5 \%$ to $18 \%$ [9].

The average diameter of right ACA was $0.22 \pm$ $0.06 \mathrm{~cm}$ and left was $0.24 \pm 0.05 \mathrm{~cm}[10]$.The discrepancy in diameter between the paired $\mathrm{A} 1$ segments was even more prevalent when one considers cases with ACoA aneurysm, where unequal diameter was present in $25 \%$ of cases[11].

W. Henry Hollinshead stated that the anterior cerebrals may be supplemented by a third, a so called middle anterior cerebral or one may be united for a part or much of their course. The ACA was occasionally, but rarely absent, more often it was double in 7 to $9 \%$ or even triple [12]. Kwak R et al reported that in 296 cases with single aneurysm of ACoA, median artery of corpus callosum were observed in 13 cases [13] and Aydin et al reported that out of 120 patients operated for ACoA aneurysm $14 \%$ had median artery of corpus callosum [7].

Azygous ACA was rare and was often associated with other intracranial anomalies such as lobar prosencephaly and saccular aneurysm [8].

Recurrent artery of Heubner was found to have its origin from the A-2 segment in $65 \%$, from the
A-1 segment in $10 \%$, and at the level of the anterior communicating artery in $25 \%$ [14].

Gomes $\mathrm{F}$ et al reported that the RAH originated from $A 2$ segment of ACA in $57 \%$ of specimens, from the junction of ACA \& ACOA in 35\% \& from A1 segment of ACA in 8\%[15]. Recurrent artery of Heubner occasionally originates from the frontopolar branch of the anterior cerebral artery [16].

Although aneurysms may arise at any bifurcation formed by distal ACA and its branches, origin of CMA is the most common site representing $50 \%-60 \%$ in all cases. The second most common site is at the origin of the frontopolar artery accounting for $10 \%-20 \%$ of cases and so measurement of the distance of origin of vessels become imperative.

In the presence of unequal diameter in $85 \%$ of cases, typically the base of the aneurysm arises on the side of larger A1 and the dome points towards the side of the hypoplastic A1.

One of the rare anomalies of anterior cerebral artery was ACA origin of ophthalmic artery [17] and middle meningeal artery[18].

\section{CONCLUSION}

Rapidly advancing fields of vascular neurosurgery and interventional neuroradiology techniques require a thorough understanding of the anatomy and it is important for the neurosurgeons and radiologists to develop a working knowledge of cerebrovascular variation. The introduction of cerebral angiography as a diagnostic technique in clinical neurology has emphasized the great importance of the distribution, course and variations of individual cerebral vessels. This detailed study done under various parameters would benefit the radiologists and neurosurgeons.

\section{ABBREVIATIONS}

ACA - Anterior Cerebral Artery

ACoA - Anterior Communicating Artery

CMA - Callosomarginal Artery

FPA - Frontopolar Artery

OFA - Orbitofrontal Artery

PCA - Pericallosal Artery

RAH - Recurrent Artery of Heubner

DACA - Distal Anterior Cerebral Artery

MACC - Median Artery of Corpus Callosum 


\section{ACKNOWLEDGEMENTS}

We would like to extend our sincere thanks to Dr. Christilda Felicia Jebakani, former Director and Professor, Institute of Anatomy, Madras Medical College, Chennai and Dr.K.Suba Ananthi, Associate Professor, Indhira Gandhi Medical College and Research Centre, Puducherry for their valuable guidance and persistent support for this study.

\section{Conflicts of Interests: None}

\section{REFERENCES}

[1]. Susan Standring. Gray's Anatomy. $40^{\text {th }}$ edition. London: Elsevier Limited; 2008;149, 297-298.

[2]. Richard Winn .H Youmans Neurological Surgery. vol 2, $5^{\text {th }}$ edition. Saunders, 1973; $1923-1926,1946$ 1947.

[3]. Martin Lehecka. Distal Anterior Cerebral Artery Aneurysms.1st edition. Helsinki University Press 2009;11

[4]. Chummy S. Sinnatamby Last's Anatomy, Regional and Applied. 10th edition. Churchill Livingstone .1999; $p-466$.

[5]. G. J. Romanes Cunningham's Textbook of Anatomy. Tenth edition. Oxford University Press.1964; p-878.

[6]. Sydney Sunderland. Neurovascular relations and anomalies at the base of the brain. J NeurolNeurosurg Psychiatry. November1948; 11(4):243-257.

[7]. Peltier J, A. Fichten, E. Havet. C. Page, P. Foulon, M. Laude Le Gars. The infra-optic course of the anterior cerebral arteries: an anatomic case report. SurgRadiolAnat, Jul2007; 29(5):389-92.

[8]. Aydin I.H, A.Onder, E.Takci, H.H. Kadioglu, C. R. Kayaoglu and Tuzun. Heubner's artery variations in anterior communicating artery aneurysms. Actaneurochirurgica, 1994; 127(1-2):17-20.
[9]. Anne G.Osborn. Diagnostic Neuroradiology, Mosby, 1994; 132-136.

[10]. Sylvia Kamath. Observations on the length and diameter of vessels forming the circle of Willis. J.Anat 1981;133(3):419-423.

[11]. Henry Hollinshead W. Anatomy for Surgeons: vol 1, The Head and Neck, 2nd edition.1968;42-46,57\&60.

[12]. Serizawa T, Saeki N, Yamaura A, Kobayashi S, Heros R, Selman M, Yasargil M.G, Ture U Microsurgical anatomy and clinical significance of the anterior communicating artery and its perforating branches. Neurosurgery.1997;40(6):1211-1218.

[13]. Kwak R, Niizuma H, Hatanaka M, Suzuki J. Anterior communicating artery aneurysms with associated anomalies. Feb1980; 52(2):162-4.

[14]. Lee KC, Rhee YK. Microsurgical Anatomy of the Proximal Anterior Cerebral Artery and Anterior Communicating Artery. J Korean Neurosurg Soc. Mar1981; 10(1):17-26.

[15]. Gomes FB, Dujovny M, Umansky F, Ausman JI, Diaz FG, Ray WJ, MirchandaniHG. Microsurgical anatomy of the recurrent artery of Heubner. J Neurosurg, Jan1984; 60(1):130-9.

[16]. Andrew H. Kaye and Peter Mcl. Black. Operative Neurosurgery, Harcourt Publishers Limited, 2000;1075\&1076.

[17]. Michael L.J. Apuzzo Brain Surgery, vol1, Churchill Livingstone Inc. 1993;764-766,769, 773.

[18]. Randy Jinkins. J Atlas of Neuroradiologic Embryology, Anatomy and Variants, Lippincott Williams \& Wilkins, 2000;25:319-321,327.

How to cite this article:

Dhanalakshmi V, Suresh Kumar T, Arun Kumar K, Sathish Kumar

S. ANTERIOR CEREBRAL ARTERY: AN ANATOMICAL STUDY. Int J

Anat Res 2019;7(2.2):6494-6498. DOI: 10.16965/ijar.2019.149 